\title{
Acquisition, Preservation and Classification (Malay Version)
}

\author{
Uqbah Iqbal* \\ Department of Life Planner, Kuala Lumpur, Malaysia

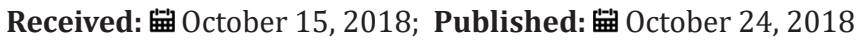 \\ *Corresponding author: Uqbah Iqbal, Department of Life Planner, Kuala Lumpur, Malaysia
}

\section{Opinion}

Written by Mohamed Salleh, insects as one of the largest and most readily available animal groups, are frequently used objects in biological learning. The living specimens' specimens are observed to know the history of life and development, physiology, behavior and ecology. The specimens that have been switched off and preserved are the materials used for the identification and diversification of the species. The ways in which the specimen can be collected, cured and well preserved is the purpose of writing this book. Collection of preserved insects is readily available at universities and research institutions in our country. The existence of a collection of haggs at school can provide exposure to students to impress and admire the existence and diversity of the species. There will be a sense of inferiority to the great Creator. It is a very interesting animal group. The diversity that exists in the form, type, way of life and the beauty of colors and colors that embellish the body creates an attraction or interest in us to recognize, study and admire the creation of these animals. Surely there will be a sense of admiration and low selfesteem towards the great Creator who creates the beings and the other beings in this.

Students, researchers and hobby enthusiasts collect various specimens for various purposes. The observation or study of a species that is still alive can be done either in laboratories or in the field. This study covers all aspects of biology such as life history, development, nutrition, reproduction, behavior and ecology. But in studying or researching the diversity of hindrances through the observation of the morphological characteristics and the anatomy of the body, then it is not necessary to do the living or freshest specimens. Teachers, faculty or researchers are well aware that it is difficult to obtain and prepare live specimens from all types of insects needed at the time for research or research material. Dead specimens are also needed and used. actually, dead specimens have long been used extensively for research and education purposes. Through a process of preserving the specimens can be well preserved and reusable when needed later. The treatment of specimens of insects stored in order to be in full condition is known as curing. Through a variety of curing methods for various types of purposes, such as teaching, exhibitions, trades, references, research and private collections.

In the field of life sciences or biological specimens it is required as an identification representative of the non-vertebral animal. Specimens specimens are required in large quantities to showcase their diversity and flexibility. The preparation of specimens or specimens of any kind of animal as a representative of a group of Animal can be easily done as it is possible to obtain any of the existing species at that time. Instead of preparing specimens to show that representatives of different species are usually in trouble. Not all the desired species are available at one time or season as a teaching material. For example, it is difficult to get specimens of dengue mosquitoes, malaria mosquitoes, warfare, or lime butterflies or other dengue needed when desired. Usually we will have difficulty getting mosquito specimens during the dry season or in pests during off-season planting. This difficulty is due to the relationship between a kind of hen with a season or a certain period of one year. In order to keep the material in place for the smooth running of the teaching, it is necessary to preserve the specimen's specimens. Temporary or permanent exhibition about public viewing is unlikely to be possible if no specimens have been preserved. These specimens should have been collected for a long period of time before being provided for the exhibition. 


\section{(c) \\ This work is licensed under Creative Commons Attribution 4.0 License}

To Submit Your Article Click Here:

Submit Article

DOI: 10.32474/CIACR.2018.05.000205

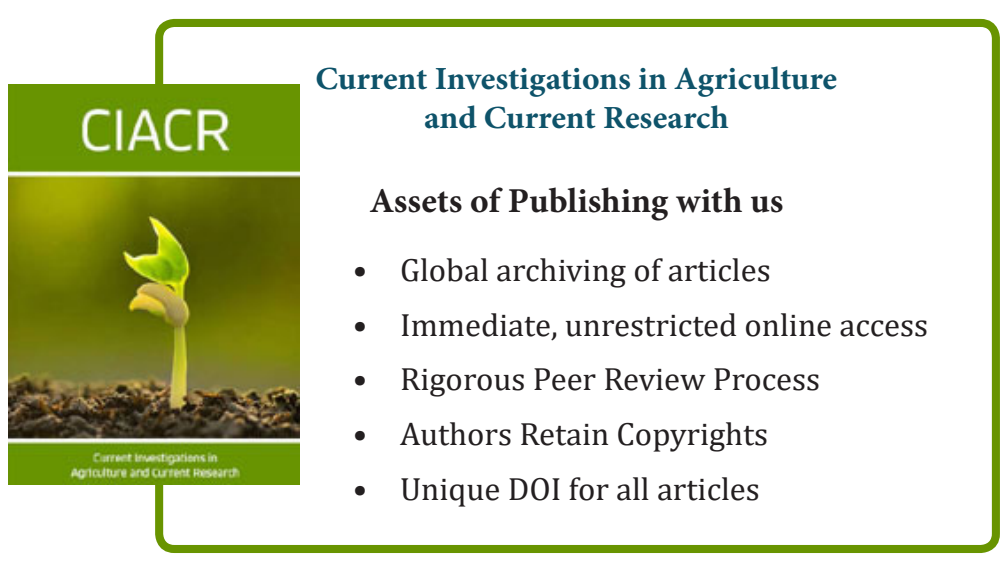

